\title{
Configurational Studies of Complexes of Tea Catechins with Caffeine and Various Cyclodextrins
}

Authors

Affiliations

Takashi Ishizu $^{1}$, Shinya Kajitani ${ }^{1}$, Hiroyuki Tsutsumi ${ }^{1}$, Takashi Sato ${ }^{1}$, Hideji Yamamoto ${ }^{2}$, Chikako Hirata

${ }^{1}$ Faculty of Pharmacy and Pharmaceutical Sciences, Fukuyama University, Fukuyama, Hiroshima, Japan

${ }^{2}$ Department of Applied Biological Science, Faculty of Engineering, Fukuyama University, Fukuyama, Hiroshima, Japan

\section{Key words}

- ent-gallocatechin-3-O-gallate

- epigallocatechin-3-O-gallate

- caffeine

- cyclodextrin

- NMR

- X-ray crystallography received Sept. 29, 2010

revised March 9, 2011

accepted March 16, 2011

\section{Bibliography}

Dol http://dx.doi.org/

10.1055/s-0030-1270982

Published online April 6, 2011

Planta Med 2011; 77:

1099-1109 ๑ Georg Thieme

Verlag KG Stuttgart · New York

ISSN 0032-0943

\section{Correspondence}

Prof. Takashi Ishizu

Laboratory of Organic and

Bio-organic Chemistry

Faculty of Pharmacy and

Pharmaceutical Sciences,

Fukuyama University

Sanzo Gakuen cho 1

Fukuyama, Hiroshima

729-0292

Japan

Phone: + 81849362111

Fax: + 81849362024

ishizu@fupharm.

fukuyama-u.ac.jp

\section{Abstract}

$\nabla$

A suspension of an equimolecular amount of entgallocatechin-3-O-gallate (entGCg) and caffeine in water afforded two kinds of crystals, which were $1: 2$ and $2: 2$ complexes of entGCg and caffeine. The stereochemical structures and intermolecular interactions between entGCg and caffeine were determined by X-ray crystallographic analysis. The crystal structure of entGCg was determined and compared with those of the $1: 2$ and $2: 2$ complexes. Epigallocatechin-3-O-gallate (EGCg) formed a $1: 1$ complex with $\beta$-cyclodextrin (CD), in which the aromatic A ring and a part of the heterocyclic $C$ ring were included from the wide secondary hydroxyl group side of the $\beta$-CD cavity in aqueous solution, while the $\mathrm{B}$ rings and 3-O-gallate groups ( $\mathrm{B}^{\prime}$ rings) were left outside the cavity. In contrast, entGCg formed a $1: 2$ complex with $\beta$ $\mathrm{CD}$, in which the aromatic $\mathrm{A}$ and $\mathrm{B}$ rings of entGCg were included by two molecules of $\beta$-CD.

Supporting information available online at http://www.thieme-connect.de/ejournals/toc/ plantamedica

\section{Introduction}

\section{$\nabla$}

Tea has been consumed worldwide since ancient times to maintain and improve health. Some evidence suggests that tea protects against lifestylerelated diseases such as cancer, high blood pressure, diabetes, obesity, and arteriosclerosis [3]. Tea prepared from leaves of the tea plant Camellia sinensis (Camelliaceae) contains various catechins and caffeine as major ingredients. Catechins are a group of polyphenols that exhibit various pharmacological activities, such as anticarcinogenic [4,5], anti-metastatic [6,7], and anti-oxidative effects $[8,9]$. The catechins in green tea are commonly classified into two categories, e.g., gallated- and non-gallated catechins, respectively, by the presence and absence of a galloyl group at the C3 position $[1,2,10]$. Generally, gallated catechins show higher activities than their non-gallated analogs [11-14].

Caffeine is an alkaloid that displays a central nervous system-stimulating effect and that forms complexes with polyphenols, especially in black tea and coffee [15-17]. Such complexes may possess a unique stereochemical structure. Thus, many researchers have been investigating the structure of such complexes. For example, Maru- yama et al. [18] noted that some gallated catechins have a high affinity for caffeine and assumed stacking of caffeine between the aromatic $\mathrm{B}$ ring and the 3-O-gallate group ( $\mathrm{B}^{\prime}$ ring). These conclusions were based on ${ }^{1} \mathrm{H}$ NMR chemical shift changes of gallate complexed to caffeine. Cai et al. [19] reported that in non-gallated-type catechins, such as catechin (CA) and epicatechin (EC), the A and $C$ rings provided a general site for caffeine association, but that in gallated-type catechins, such as ent-catechin-3-O-gallate (entCg) and epigallocatechin-3-O-gallate (EGCg), the gallate moiety is the preferred site for complexation ( $\bullet$ Fig. 1 ). Furthermore, Hayashi et al. [20] reported the participation of the A ring as well as $\mathrm{B}$ ring or 3-O-gallate groups ( $\mathrm{B}$ ' ring) in the complexation with caffeine as concluded from ${ }^{1} \mathrm{H}$ NMR chemical shift differences, nuclear Overhauser enhancement, and exchange spectroscopy (NOESY) spectra. However, the overall structure of the complex and the detailed intermolecular interactions between catechin and caffeine have not been elucidated sufficiently.

In this study, the crystal structure of the complex between entGCg and caffeine was determined by $\mathrm{X}$-ray crystallography, and the intermolecular in- 
<smiles>O=C(O[C@H]1Cc2c(O)cc(O)cc2O[C@H]1c1cc(O)c(O)c(O)c1)c1cc(O)c(O)c(O)c1</smiles>

ent-Gallocatechin-3-O-gallate (entGCg)<smiles>C[C@@H](c1cc(O)c(O)c(O)c1)C(C)(C)OC(=O)c1cc(O)c(O)c(O)c1</smiles>

Epigallocatechin-3-O-gallate (EGCg)<smiles>Cn1c(=O)c2c(ncn2C)n(C)c1=O</smiles>

Caffeine

Fig. 1 Ent-gallocatechin-3-O-galate (entGCg), epigallocatechin-3-O-gallate (EGCg), and caffeine.

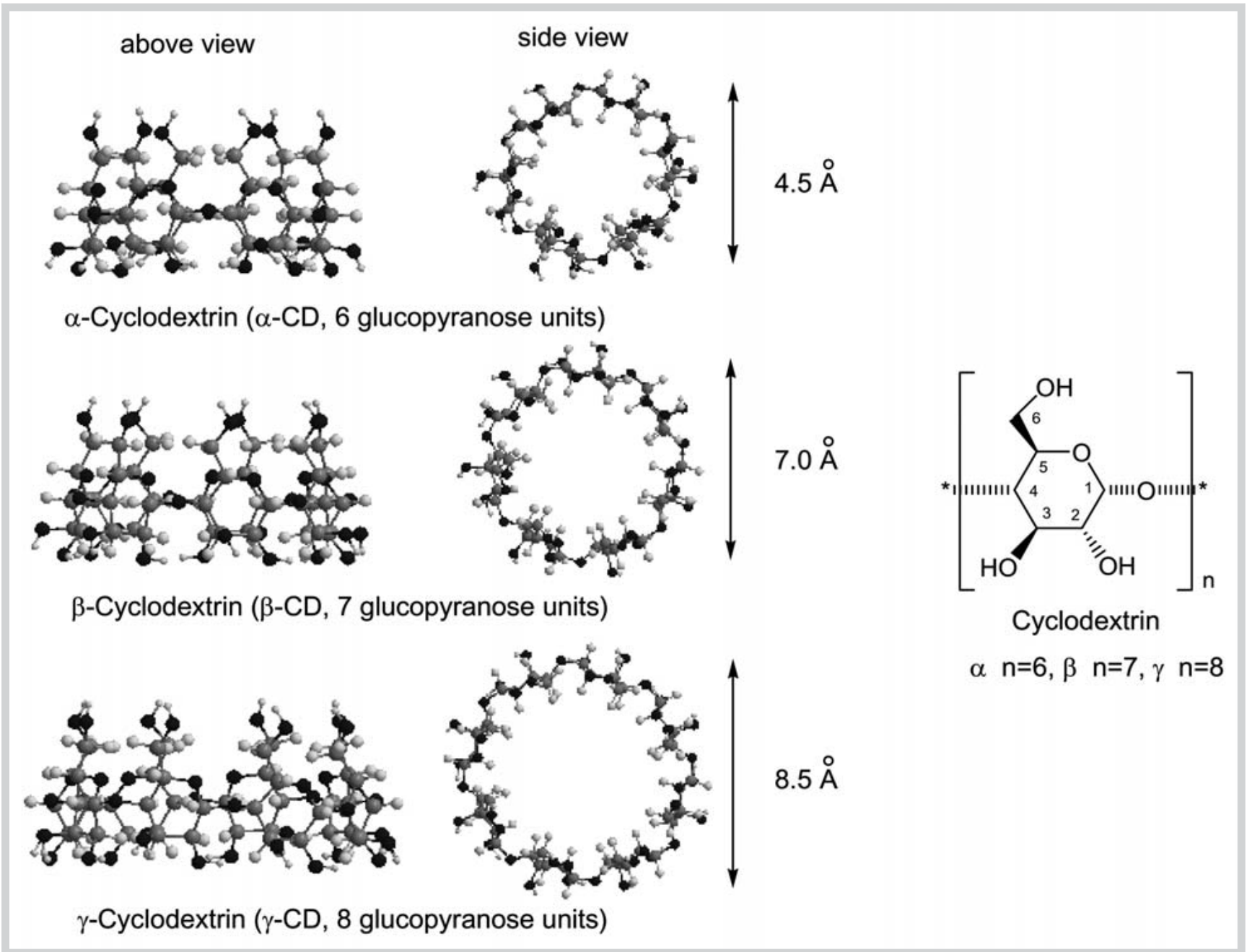

Fig. 2 Various cyclodextrins.

teractions between entGCg and caffeine moieties were also elucidated [21-23].

A further study focused on the inclusion complexes comprising cyclodextrins and catechins. Cyclodextrins (CDs) are cyclic oligosaccharides which have six, seven, and eight D-(+)-glucopyranose units for $\alpha-, \beta$-, and $\gamma$-CDs, respectively ( $\bullet$ Fig. 2). CDs incorporate compounds in their hydrophobic cavities depending on the cavity size. The inclusion complexes alter the physical, chem- ical, and biological properties of the guest molecule and may yield complexes that have considerable medicinal potential [24]. Special interest has been paid to EGCg, a major green tea component with a broad spectrum of bioactivities. However, catechin powders are bitter, brown and are easily oxidized, making them difficult to use as a medicine or natural food additive. In order to overcome these problems, we investigated the fundamental properties of the inclusion complexes of $\alpha-, \beta-$, and $\gamma$-CDs with 


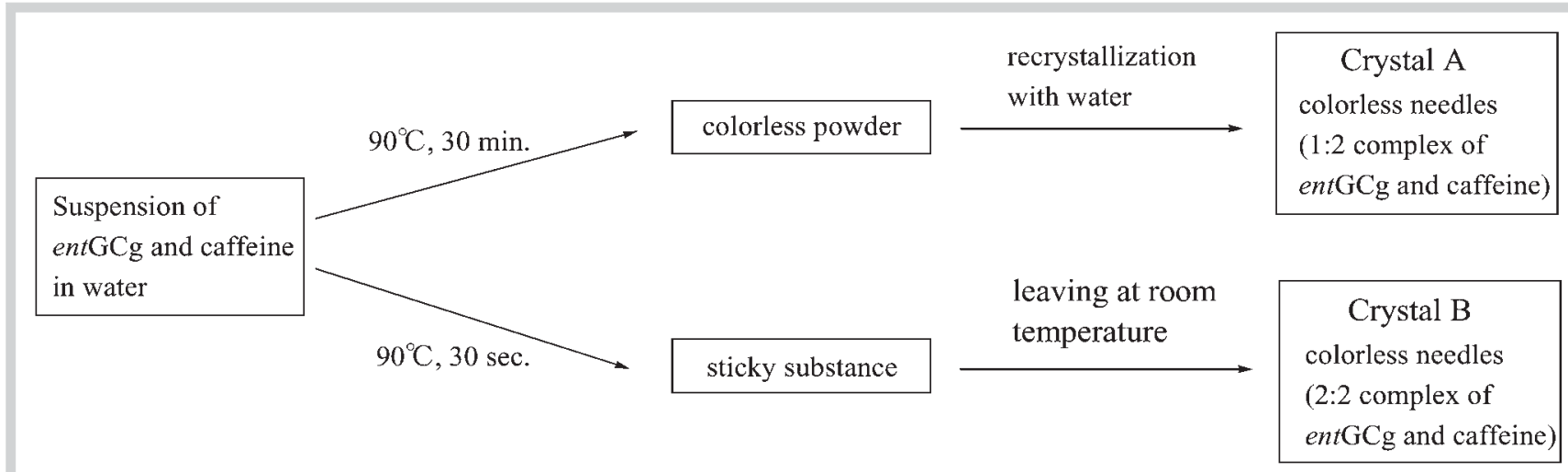

Fig. 3 Preparation of two kinds of crystal of complexes of entGCg and caffeine.

entGCg and EGCg in aqueous solution using a combination of NMR techniques and theoretical approaches [25-27]. EntGCg is a diastereomer of EGCg, differing in the configuration at $\mathrm{C} 2$. The difference between the inclusion complexes is discussed in relation to their conformations in aqueous solution.

\section{The Two Complexes of entCCg and Caffeine [21-23] $\nabla$}

An aqueous suspension containing an equimolecular amount of entGCg and caffeine in water was heated at $90^{\circ} \mathrm{C}$ for $30 \mathrm{~min}$. The solution gave a colorless powder ( Fig. 3 ), which was recrystallized from water to give colorless needles (crystal A, mp 160$162^{\circ} \mathrm{C}$ ). The crystals represented a complex of entGCg and caffeine in a molar ratio of $1: 2$ based on the measurement of the integral area of ${ }^{1} \mathrm{H}$ NMR signals. When the same suspension was heated at $90^{\circ} \mathrm{C}$ for $30 \mathrm{~s}$ and left at room temperature, a sticky substance was obtained ( Fig. 3), comprising a complex of entGCg, caffeine, and water in a molar ratio of $1: 1: 22$ as evident from the integrals of ${ }^{1} \mathrm{H}$ NMR signals. The sticky material crystallized slowly over a period of ca. three months at room temperature to give colorless needles (crystal $\mathrm{B}, \mathrm{mp} 155-157^{\circ} \mathrm{C}$ ) which contained complexes of entGCg and caffeine in a molar ratio of $1: 1$ based on measurement of the integral area of ${ }^{1} \mathrm{H}$ NMR signals. However, it was actually a 2:2 complex of entGCg and caffeine based on evidence from X-ray crystallography [22]. Interestingly, when the sticky substance was heated at $90^{\circ} \mathrm{C}$ for $30 \mathrm{~min}$, the product contained entGCg and caffeine in a molar ratio of $1: 2$ and was recrystallized from water to give colorless needles (crystal A). It was concluded that the complex formation energy of the $1: 2$ complex was higher than that of the $2: 2$ complex. Crystallizations of EGCg and caffeine have been also attempted, but they did not yet succeed.

An ORTEP drawing and a one unit cell of the $1: 2$ complex of entGCg and caffeine ( $\odot$ Fig. 4 a) show that two caffeine molecules were located above the aromatic $\mathrm{A}$ ring and the 3-O-gallate group (B' ring) of an entGCg molecule. In one unit cell, four $1: 2$ complex entities and twelve water molecules as the crystal solvent were present. In a unit of the merohedral twinned structure [28] of crystal $B$ with $2: 2$ complexes, the $A$ and $C$ rings of the two ent $\mathrm{Cg}$ molecules faced each other, and their aromatic $\mathrm{B}$ rings and 3-Ogallate groups ( $\mathrm{B}^{\prime}$ rings) faced the two caffeine molecules ( Fig. 4b). One unit cell contained eight units consisting of the
$2: 2$ complex and ninety-six water molecules as the crystal solvent.

To compare the crystal structures of the $1: 2$ and $2: 2$ complexes, we carried out X-ray analysis of entGCg alone, which was crystallized using the different solubility between entGCg and EGCg in water. A solution containing an equimolecular amount of entGCg and EGCg was left at room temperature for a few days to afford a colorless block-shaped single crystal of only entGCg, while EGCg as well as some entGCg were still soluble in the solution. The single crystal of entGCg was determined by X-ray crystallographic analysis [21]. One unit cell contains two entGCg molecules and two water molecules ( $\bullet$ Fig. 5).

The dihedral angles of $\mathrm{C}^{\prime}-\mathrm{C} 2-\mathrm{C} 3-\mathrm{O}$ and $\mathrm{H} 2-\mathrm{C} 2-\mathrm{C} 3-\mathrm{H} 3$ of the entGCg moiety of the $1: 2$ complex are $55.93^{\circ}$ and $173.18^{\circ}$, respectively, indicating that the $\mathrm{B}$ ring and the 3-O-gallate group ( $\mathrm{B}$ ' ring) both adopt equatorial positions ( Fig. 6; $\bigcirc$ Table 1 ). This also holds true for the $2: 2$ complex, whereas the corresponding aromatic rings of entGCg crystals alone adopt axial and pseudoaxial positions, respectively ( Fig. 6; $\bigcirc$ Table 1 ). These findings suggested a conformational change of entGCg upon conversion of $1: 2$ to $2: 2$ complexes, facilitated by the conformational flexibility of entGCg molecules owing to puckering of the pyran $\mathrm{C}$ ring. On the other hand, the caffeine molecule has a planar and rigid xanthine skeleton.

For complex formation of compounds with aromatic rings, three kinds of interactions are important, namely face-to-face $\pi-\pi$ interaction between the planes of two aromatic rings, offset $\pi-\pi$ interaction between the planes of two slightly shifted aromatic rings, and $\mathrm{CH}-\pi$ interaction ( $\bullet$ Fig. 7).

A marked difference in the layer structure between the crystal structures of the $1: 2$ and $2: 2$ complexes and entGCg alone was observed ( Figs. 8-11). As shown in $\odot$ Fig. 8, units of the former piled up in parallel in the same direction as the a-axis. The distances between the aromatic $\mathrm{A}$ rings and the 3-O-gallate groups (B' rings) of two entGCg molecules were 6.866 and $6.767 \AA$, respectively. Two caffeine molecules were located almost in the middle of the A ring and 3-O-gallate group (B' ring) of entGCgs in a sandwich-like manner. This allows for face-to-face $\pi-\pi$ interactions between the $\mathrm{A}$ ring and the 3-O-gallate group ( $\mathrm{B}^{\prime}$ ring) of the upper entGCg and the six-membered ring of caffeine, and offset $\pi-\pi$ interactions between the same structural elements involving the lower entGCg. Also, a $\mathrm{CH}-\pi$ interaction was formed between the $\mathrm{B}$ ring of the lower entGCg and the methyl group at N7 of caffeine (distance 3.281 $\AA$ ). As shown in $\odot$ Table 2, three in- 


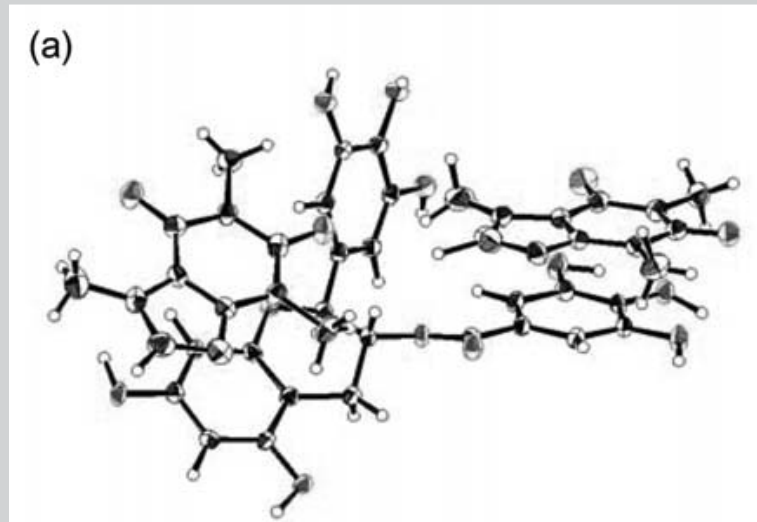

(b)
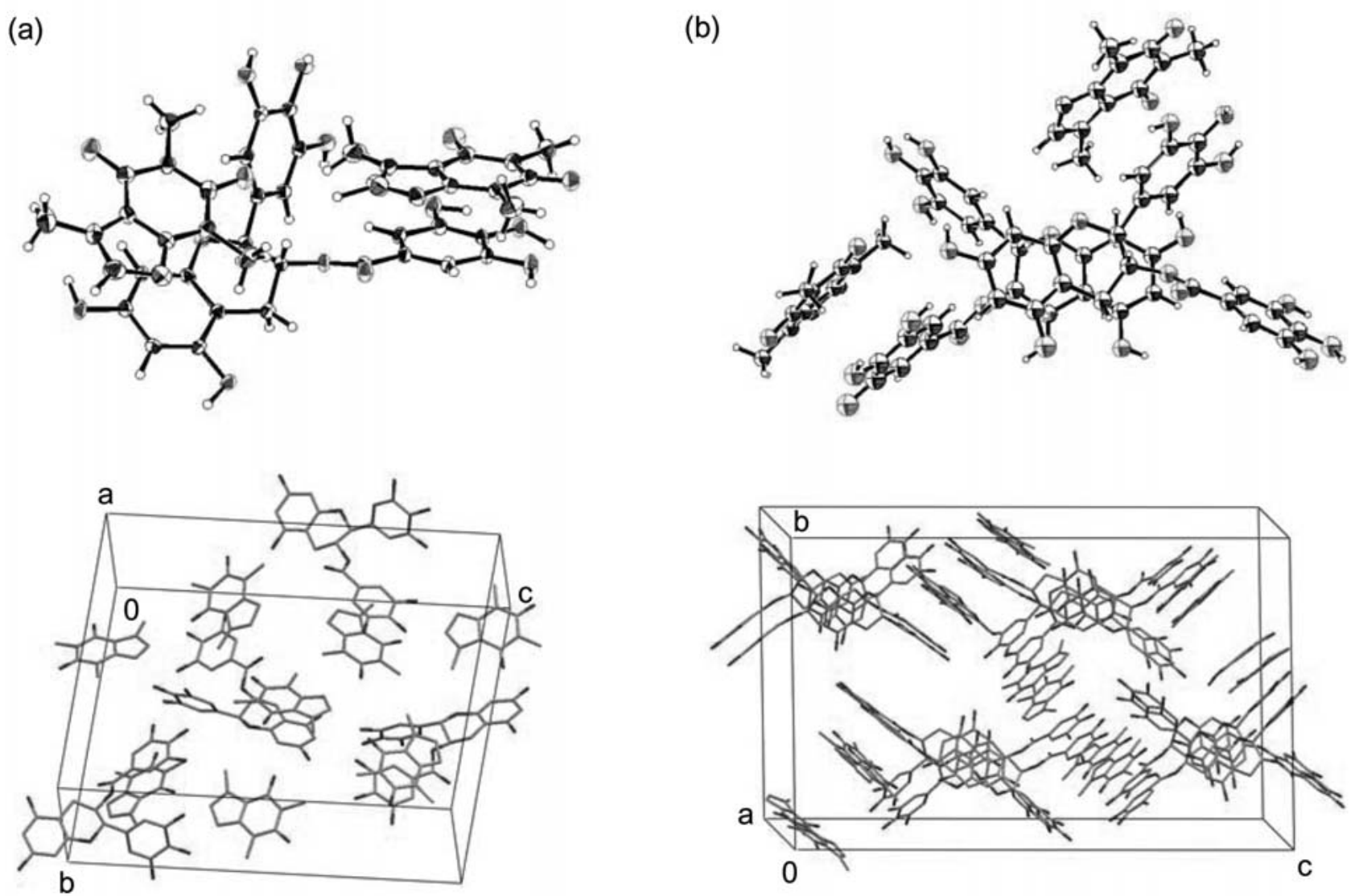

\section{1:2 complex of entGCg and caffeine}

Fig. $4 \mathbf{a}$ and $\mathbf{b}$ Crystal structure of the $1: 2$ (a) and 2:2 (b) complexes of entGCg and caffeine, ORTEP drawing with thermal ellipsoids at a $30 \%$ proba- bility level and one unit cell. Hydrogen atoms and crystal solvent are omitted for clarity. (a)

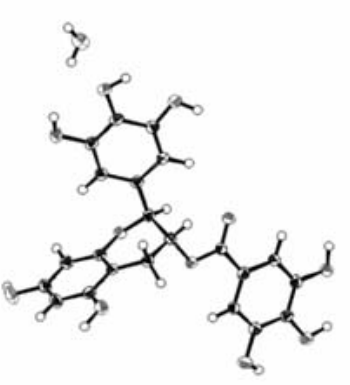

(b)

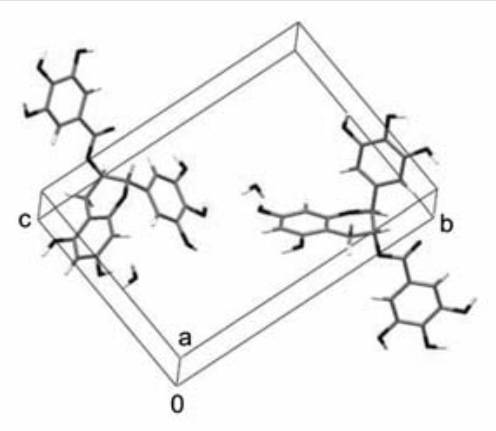

Fig. $\mathbf{5}$ a and $\mathbf{b}$ Crystal structure of entGCg alone (a) ORTEP drawing with thermal ellipsoids at a $30 \%$ probability level. b One unit cell. Hydrogen atoms and crystal solvent are omitted for clarity. termolecular hydrogen bonds between entGCg and caffeine, and entGCgs were observed in the $1: 2$ complex.

In Fig. 9, packing of the $2: 2$ complex of entGCg and caffeine in the cell down the a-axis is shown. Each caffeine molecule and the aromatic $\mathrm{B}$ ring and 3-O-gallate group (B' ring) of the entGCg molecules were arrayed regularly in the following order: 3-O-gallate group (B' ring), caffeine, 3-O-gallate group (B' ring), caffeine, and $B$ ring. The average distances between each ring were ca. 3.2 Å, ca. $3.3 \AA$, ca. $3.3 \AA$, and ca. $3.4 \AA$, respectively. Furthermore, these caffeine molecules were surrounded on four sides by the aromatic $\mathrm{B}$ rings and the 3-O-gallate groups ( $\mathrm{B}$ ' rings) of two entGCg molecules.

In the layer structure, units of the $2: 2$ complex of entGCg and caffeine piled up in parallel to the a-axis, and the A and A rings of entGCgs faced each other by face-to-face $\pi-\pi$ interactions ( Fig. 10). All caffeine molecules were sandwiched between the aromatic $\mathrm{B}$ ring and the 3-O-gallate group ( $\mathrm{B}^{\prime}$ ring) or the 3-Ogallate groups (B' rings) of entGCg molecules by face-to-face $\pi-\pi$ interactions. Also, $\mathrm{CH}-\pi$ interactions occurred between the $\mathrm{B}$ rings of ent $\mathrm{GCg}$ and both the methyl groups at N3 (average dis- 


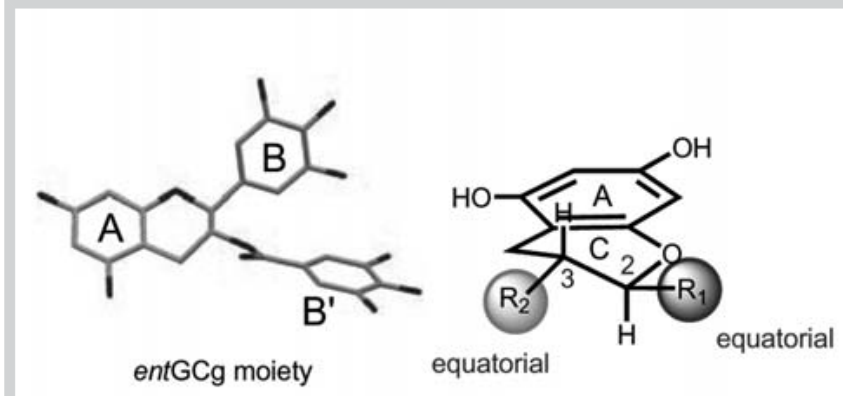

Conformation of entGCg moieties in 1:2 and 2:2 complexes

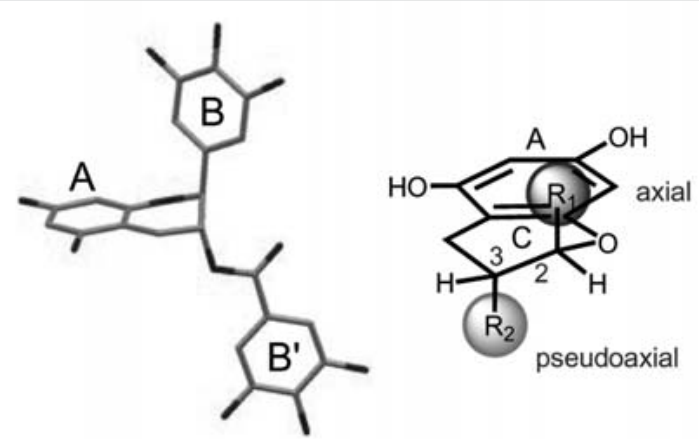

Conformation of entGCg alone
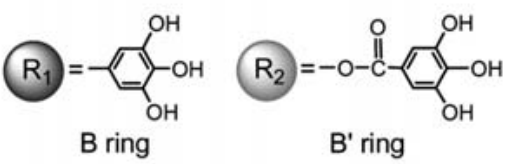

Fig. 6 Conformation of entGCg moieties in the 1:2 and 2:2 complexes, and entGCg alone in crystal state.

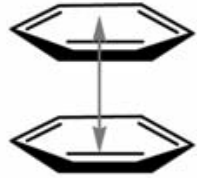

face-to-face $\pi-\pi$ interaction

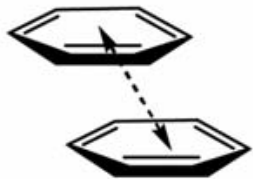

offset $\pi-\pi$ interaction

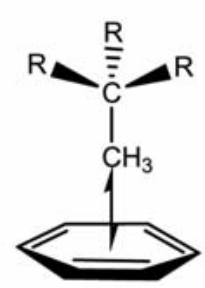

$\mathrm{CH}-\pi$ interaction

Fig. 7 Intermolecular interactions by non-covalent bonds in the complexes of catechins and caffeine.<smiles>O=C(O[C@H]1Cc2c(O)cc(O)cc2O[C@H]1c1cc(O)c(O)c(O)c1)c1cc(O)c(O)c(O)c1</smiles>

ent-gallocatechin-3-O-gallate (entGCg)<smiles>Cn1c(=O)c2c(ncn2C)n(C)c1=O</smiles>

plane aromatic compound caffeine

\begin{tabular}{|c|c|c|c|}
\hline & Torsion angle (C1'-C2-C3-O) & Torsion angle ( $\mathrm{H} 2-\mathrm{C} 2-\mathrm{C} 3-\mathrm{H} 3)$ & Table 1 Torsion angle in entGCg \\
\hline 1:2 Complex of entGCg and caffeine & $55.93^{\circ}$ & $173.18^{\circ}$ & in the $1: 2$ and $2: 2$ complexes and \\
\hline 2:2 Complex of entGCg and caffeine & $61.05^{\circ}$ (average) & $176.94^{\circ}$ (average) & entGCg alone. \\
\hline entGCg alone & $159.03^{\circ}$ & $72.80^{\circ}$ & \\
\hline
\end{tabular}

tance ca. 3.0 $\AA$ ) and N7 of caffeine (average distance ca. $2.8 \AA$ ). As shown in Table 3, eight intermolecular hydrogen bonds between entGCgs, entGCg and caffeine were observed in this case. In the layer structure, entGCg faced in the same direction and accumulated parallel to the a-axis ( Fig. 11). Offset $\pi-\pi$ interactions formed between $\mathrm{A}$ and $\mathrm{A}$ rings, $\mathrm{B}$ and $\mathrm{B}$ rings and 3-O-gal- late groups (B' rings) of entGCg molecules. However, no face-toface $\pi-\pi$ interaction was observed in the layer of entGCg. Furthermore, five hydrogen bonds were observed between entGCgs, entGCg and water and, as a result, a network of hydrogen bonds was formed in the crystal structure of entGCg ( Table 4). Generally speaking, the equatorial position of a bulky group is kineti- 

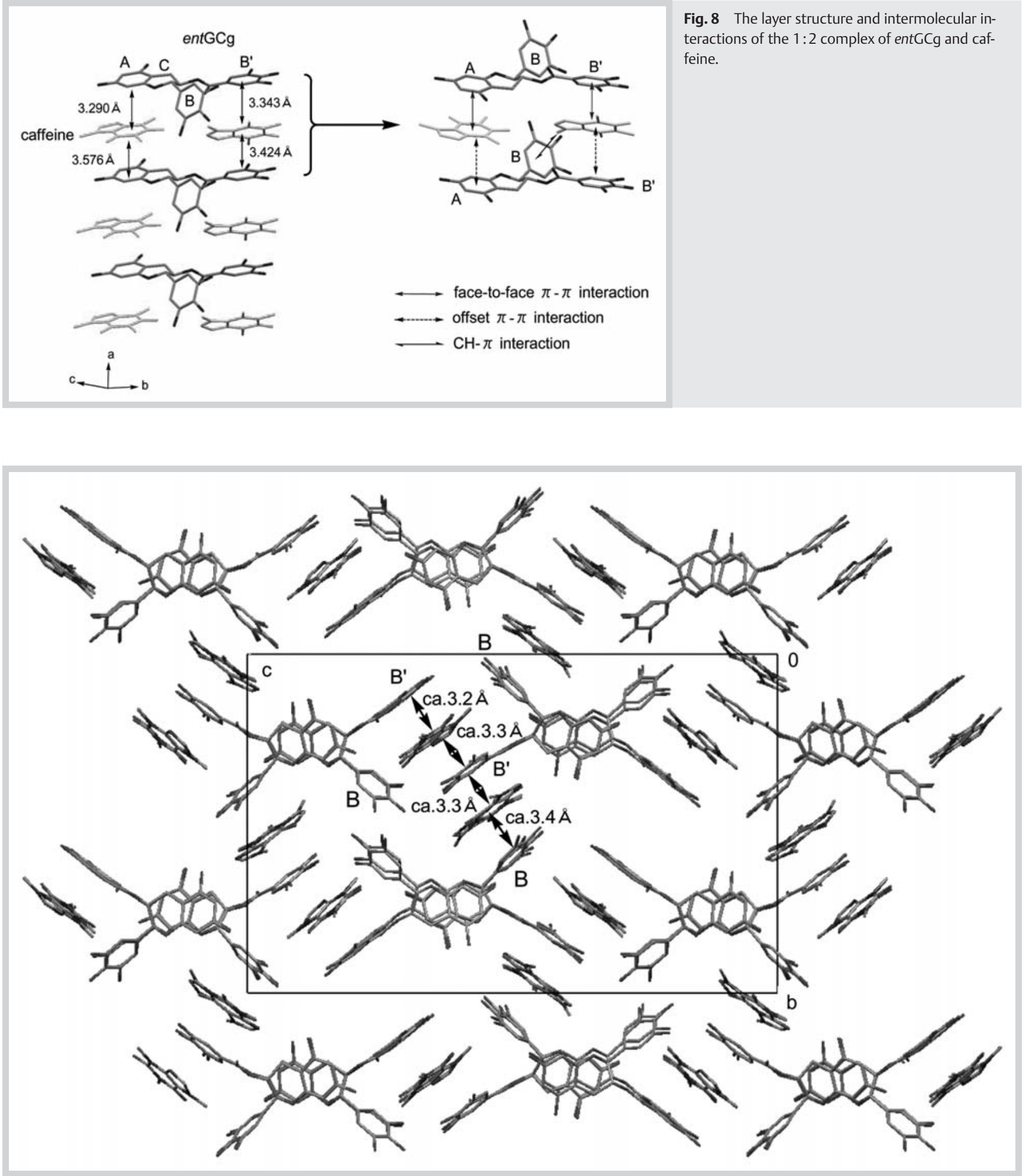

Fig. 9 Packing of the 2:2 complex of entGCg and caffeine in the cell down the a-axis.

\begin{tabular}{|c|c|c|c|c|c|c|}
\hline D-H & A & D...A & D-H & H...A & $\angle \mathrm{D}-\mathrm{H}$...A & Table 2 Intermolecular hydrogen \\
\hline $\mathrm{C}(4)-\mathrm{OH}(2 \mathrm{O})$ & $\mathrm{O}(14)$ & 2.727 & 1.108 & 1.656 & 160.81 & bonds in the $1: 2$ complex. \\
\hline $\mathrm{C}(6)-\mathrm{OH}(3 \mathrm{O})$ & $\mathrm{O}(7)$ & 2.880 & 1.045 & 1.710 & 157.97 & \\
\hline $\mathrm{C}(20)-\mathrm{OH}(100)$ & $\mathrm{O}(5)$ & 2.894 & 1.059 & 1.870 & 161.49 & \\
\hline
\end{tabular}




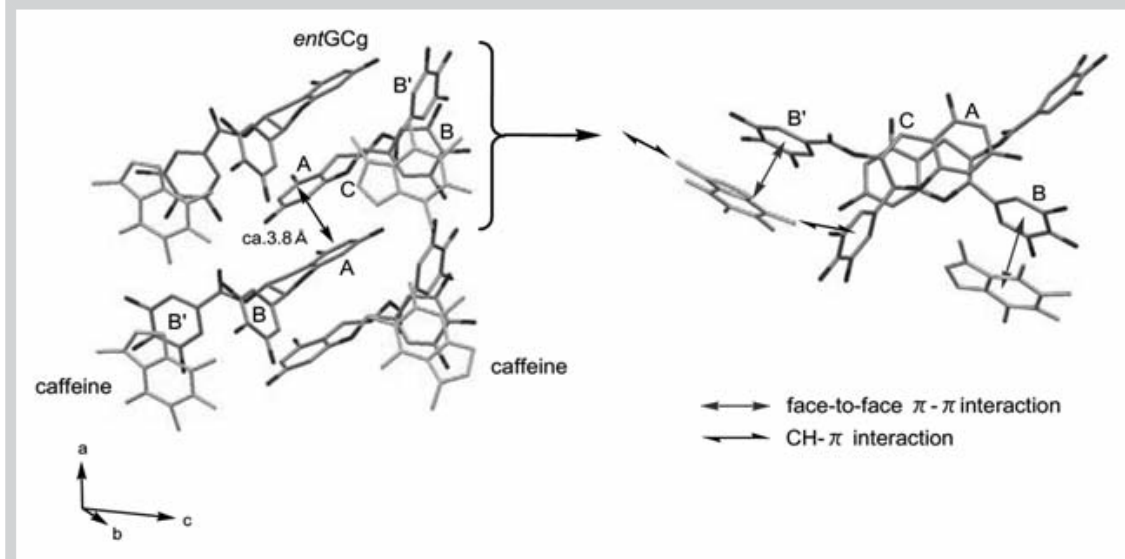

Fig. 10 The layer structure and intermolecular interactions of the $2: 2$ complex of entGCg and caffeine.
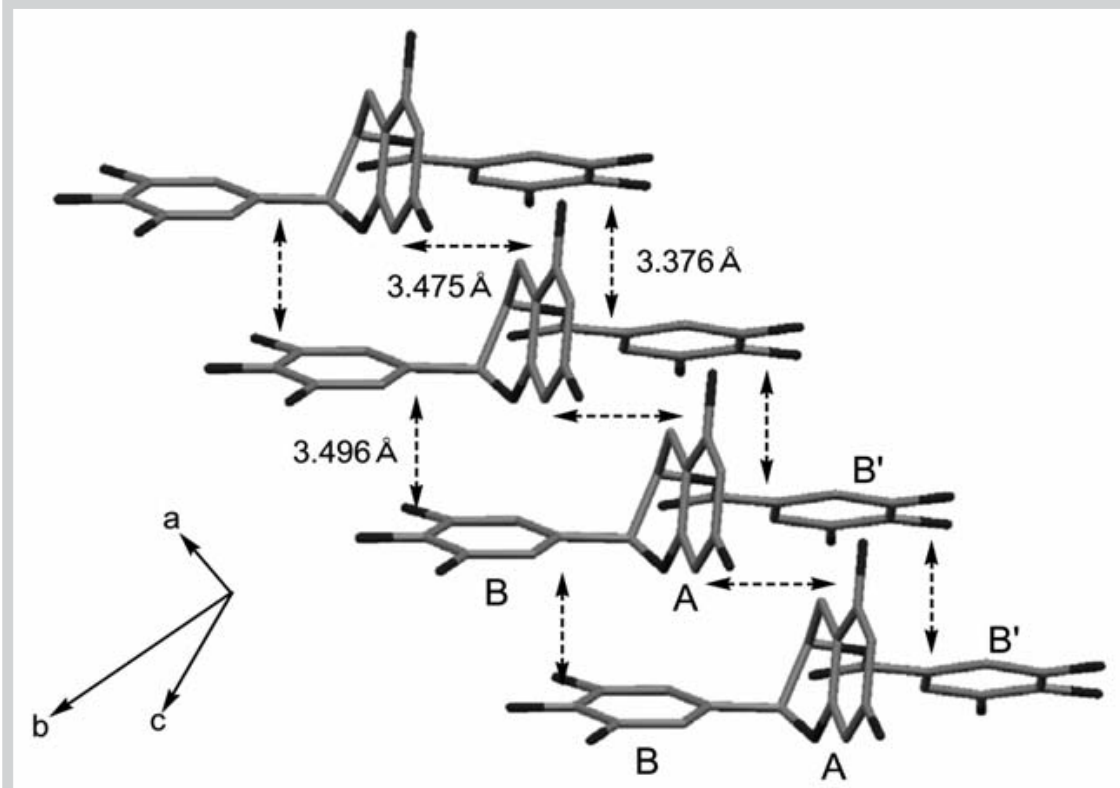

Fig. 11 The layer structure and intermolecular interaction of ent $\mathrm{GCg}$ alone.

$\leftrightarrow \cdots \rightarrow$ offset $\pi-\pi$ interaction

\begin{tabular}{llllll}
\hline D-H & A & D...A & D-H & H...A & < D-H...A \\
\hline $\mathrm{C}(36)-\mathrm{OH}(16)$ & $\mathrm{N}(27)$ & 2.729 & 0.841 & 1.891 & 174.83 \\
\hline $\mathrm{C}(42)-\mathrm{OH}(18)$ & $\mathrm{O}(78)$ & 2.660 & 0.840 & 1.830 & 169.96 \\
\hline $\mathrm{C}(96)-\mathrm{OH}(42)$ & $\mathrm{O}(13)$ & 2.657 & 0.839 & 1.818 & 177.62 \\
\hline $\mathrm{C}(104)-\mathrm{OH}(46)$ & $\mathrm{O}(39)$ & 2.513 & 0.840 & 1.705 & 160.36 \\
\hline $\mathrm{C}(109)-\mathrm{OH}(48)$ & $\mathrm{O}(3)$ & 2.816 & 0.839 & 2.058 & 149.88 \\
\hline $\mathrm{C}(186)-\mathrm{OH}(81)$ & $\mathrm{O}(52)$ & 2.621 & 0.840 & 1.781 & 177.90 \\
\hline $\mathrm{C}(194)-\mathrm{OH}(85)$ & $\mathrm{O}(26)$ & 2.657 & 0.841 & 1.820 & 173.58 \\
\hline $\mathrm{C}(224)-\mathrm{OH}(98)$ & $\mathrm{O}(65)$ & 2.570 & 0.842 & 1.740 & 168.46 \\
\hline
\end{tabular}

Table 3 Intermolecular hydrogen bonds in the $2: 2$ complex.

\begin{tabular}{llllll}
$\mathbf{D}-\mathbf{H}$ & A & D...A & D-H & H...A & < D-H...A \\
\hline $\mathrm{C}(7)-\mathrm{OH}(7)$ & $\mathrm{O}(8)$ & 2.728 & 1.014 & 1.750 & 160.77 \\
\hline $\mathrm{C}(15)-\mathrm{OH}(12)$ & $\mathrm{O}(4)$ & 2.801 & 0.919 & 1.933 & 156.53 \\
$\mathrm{C}(19)-\mathrm{OH}(15)$ & $\mathrm{O}(11)$ & 2.694 & 0.972 & 1.746 & 164.30 \\
\hline $\mathrm{C}(20)-\mathrm{OH}(16)$ & $\mathrm{O}(5)$ & 2.734 & 0.953 & 1.810 & 162.29
\end{tabular}

Table 4 Intermolecular hydrogen bonds in entGCg alone. 


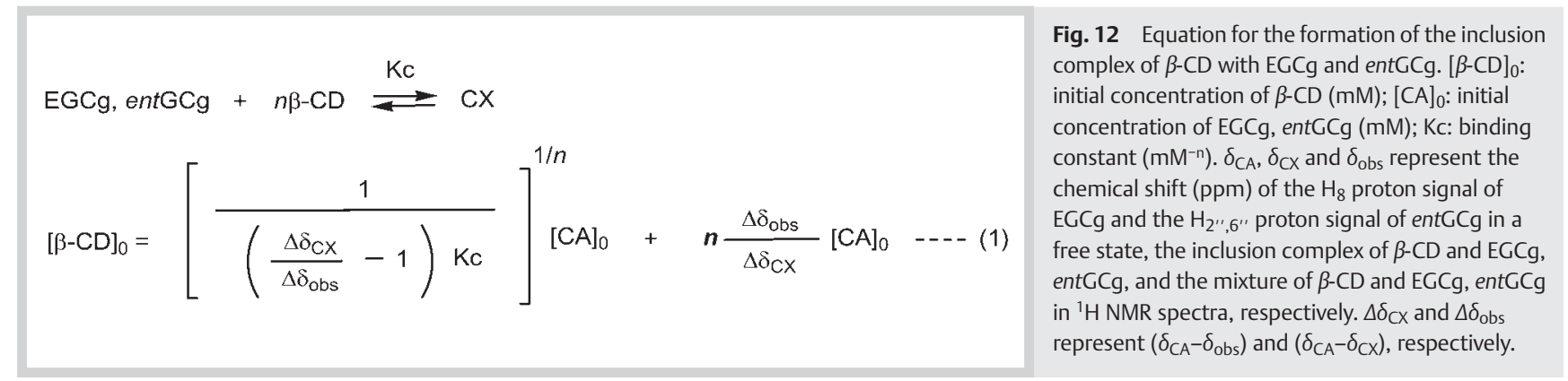

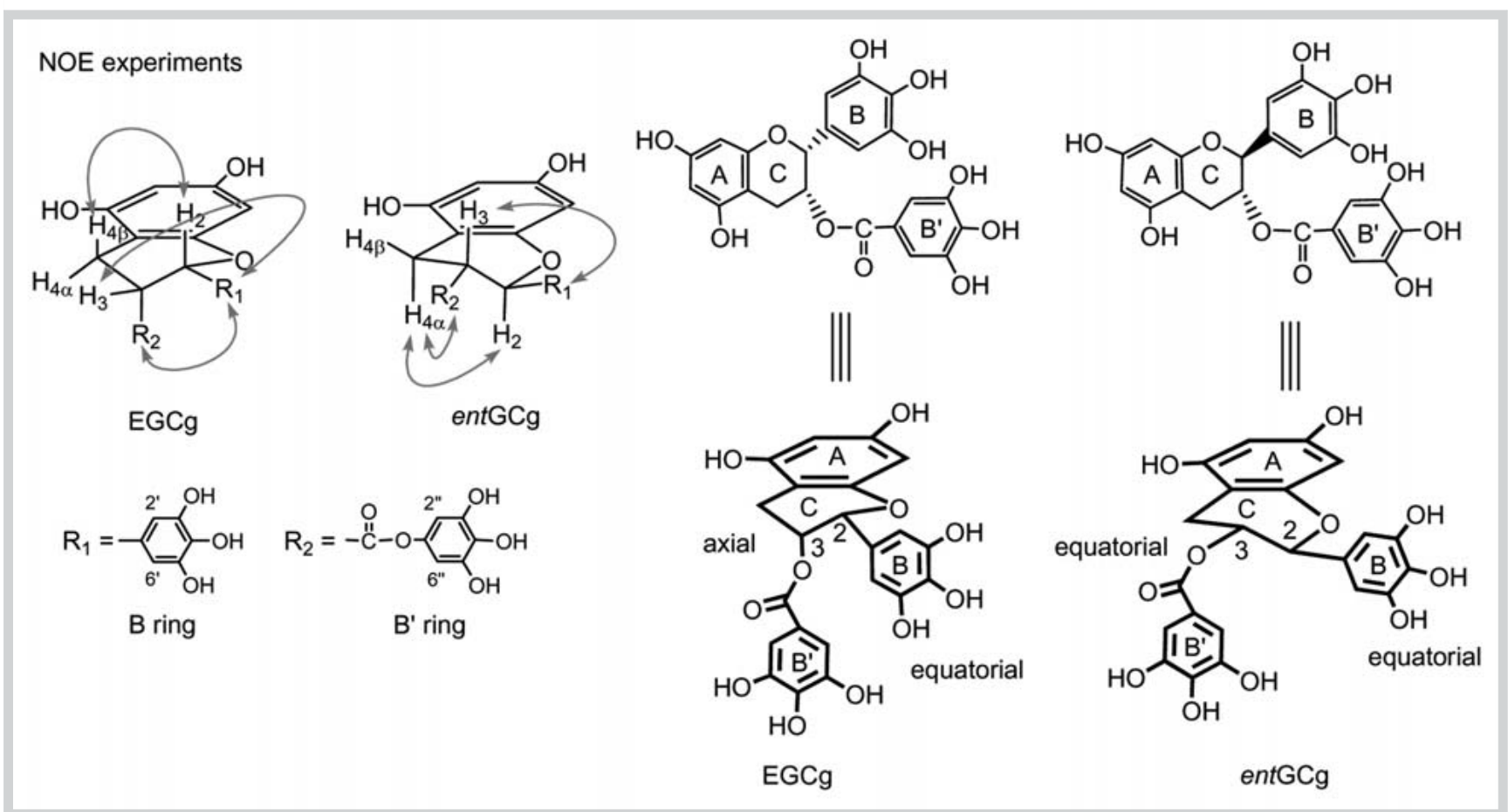

Fig. 13 Conformation of EGCg and entGCg in aqueous solution. Measurement temperature of NOE experiments was $35^{\circ} \mathrm{C}$.

cally more stable than the axial position, but it is thought that the cooperative effect of these interactions permits axial and pseudoaxial positions of the $\mathrm{B}$ ring and the 3 - $O$-gallate group ( $\mathrm{B}^{\prime}$ ring).

\section{Inclusion Complexes of Various Cyclodextrins with EGCg and entGCg [26-28]

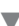

Equation (1) for the formation of the inclusion complex of $\beta-C D$ with EGCg and entGCg was constructed to calculate the respective $n$ values ( $\odot$ Fig. 12), which were 1.20 and 1.90 for EGCg and entGCg at $35^{\circ} \mathrm{C}$, respectively. This suggested that the stoichiometry of the formation of the inclusion complex of $\beta$-CD with EGCg was mainly $1: 1$, a conclusion that was supported by Job's Plot experiments [29]. In contrast, the stoichiometric composition of the inclusion complex of $\beta$-CD with entGCg was mainly $1: 2$.

The conformation of EGCg and entGCg in aqueous solution were investigated. In the ${ }^{1} \mathrm{H}$ NMR spectrum of EGCg, the signal for $\mathrm{H}_{2}$ appeared as a broad singlet, indicating that the coupling constant $\mathrm{J}_{2,3}$ was ca. $0 \mathrm{~Hz}$. The dihedral angle $\angle \mathrm{H}_{2}-\mathrm{C}_{2}-\mathrm{C}_{3}-\mathrm{H}_{3}$ was expected to be approximately $90^{\circ}$ as judged from the Karplus equation
[30]. - Fig. 13 shows the results of the nuclear Overhauser effect (NOE) differential analysis of EGCg and entGCg in $\mathrm{D}_{2} \mathrm{O}$ at $35^{\circ} \mathrm{C}$.

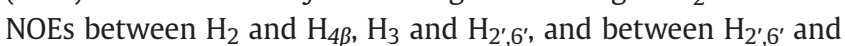
$\mathrm{H}_{2 " \text { "6"6 }}$ of EGCg suggested that the aromatic $\mathrm{B}$ ring and the 3 - $\mathrm{O}$-gallate groups (B' rings) of EGCg adopt equatorial and axial positions, respectively.

In the ${ }^{1} \mathrm{H}$ NMR spectrum of entGCg, the $\mathrm{H}_{2}$ signal appeared as a doublet $\left(\mathrm{J}_{2,3}=6.5 \mathrm{~Hz}\right)$. As shown in Fig. 13, NOEs between $\mathrm{H}_{2}$

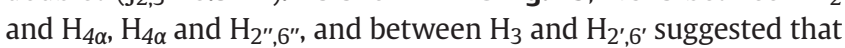
the aromatic $\mathrm{B}$ ring and 3-O-gallate groups ( $\mathrm{B}$ ' rings) were both in equatorial positions and therefore much more distant when compared with EGCg.

To determine the structure of the $1: 1$ inclusion complex of EGCg and $\beta-C D$, rotating frame nuclear Overhauser effect spectroscopy (ROESY) of a solution containing equimolar amounts of $\beta-C D$ and EGCg in $\mathrm{D}_{2} \mathrm{O}$ was measured. Strong intermolecular ROE correlations between the $\mathrm{H}_{8}$ of EGCg and the $\mathrm{H}_{3}, \mathrm{H}_{5}$, and $\mathrm{H}_{6}$ being on the inner surface of $\beta$-CD suggested that the A ring of EGCg was included in the $\beta$-CD cavity. Furthermore, intermolecular ROE correlations between $\mathrm{H}_{2^{\prime}, 6^{\prime}}$ of EGCg and each $\beta$-CD proton were detected. Based on the results of the ROESY spectrum and the ${ }^{1} \mathrm{H}$ 

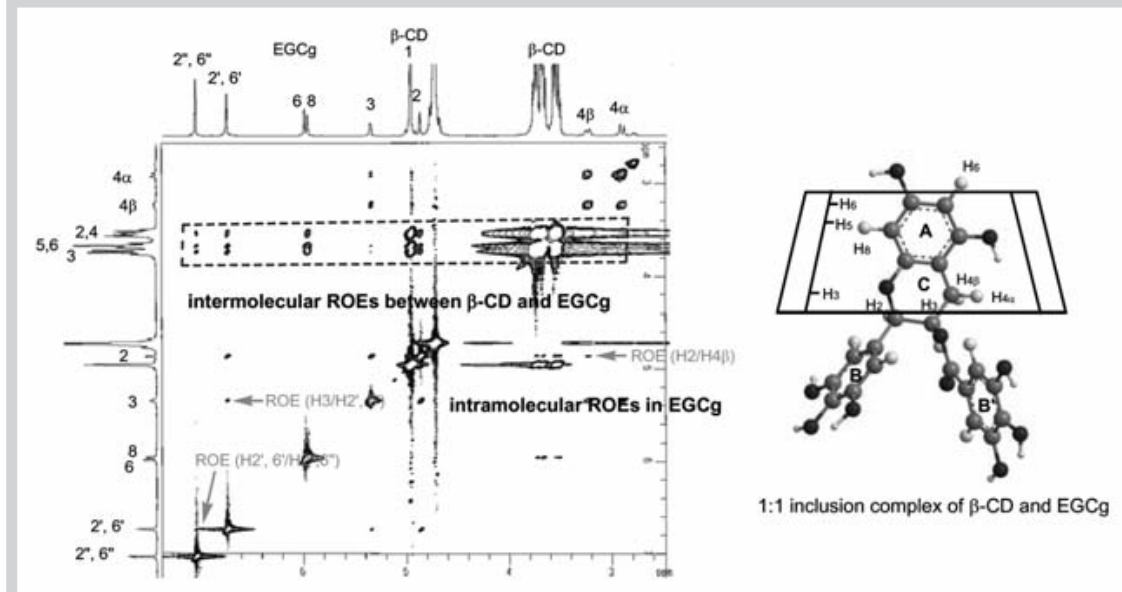

Fig. 14 ROESY spectrum of a solution containing an equimolecular amount of $\beta-C D$ and EGCg in $\mathrm{D}_{2} \mathrm{O}$ at $35^{\circ} \mathrm{C}$, and possible structure of $1: 1$ inclusion complex of $\beta$-CD and EGCg.

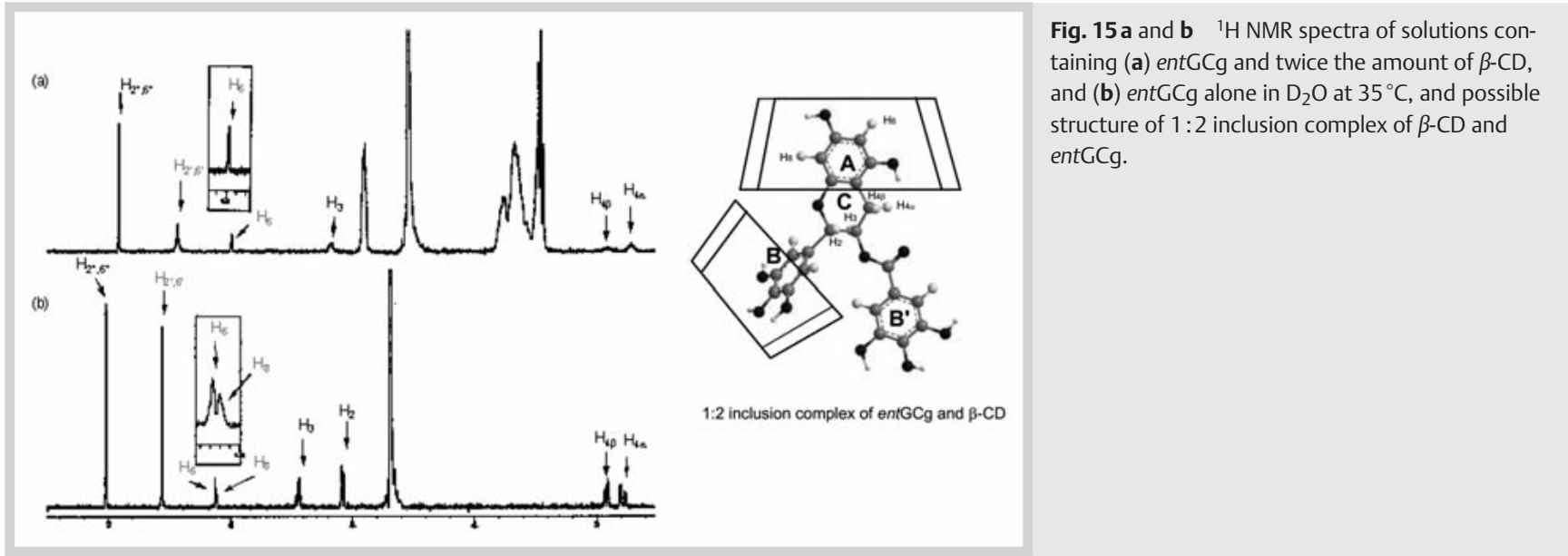

NMR chemical shift changes [24], it was concluded that the A ring and a part of the $C$ ring of EGCg were included in the wide secondary hydroxyl group side of the $\beta$-CD cavity, and that the aromatic $B$ ring and 3-O-gallate group ( $B$ ' ring) were left outside the cavity ( Fig. 14). Also, EGCg intramolecular associations be-

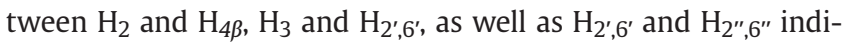
cated that the conformation in which the $\mathrm{B}$ ring and $3-\mathrm{O}$-gallate group ( $\mathrm{B}$ ' ring) of EGCg adopted equatorial and axial positions, respectively, were still maintained upon the formation of the inclusion complex.

In the ROESY spectrum of a solution containing entGCg and $\beta$-CD (ratio $1: 2$ ) in $\mathrm{D}_{2} \mathrm{O}$, strong intermolecular ROE correlations between the $\mathrm{H}_{8}$ of entGCg and the $\mathrm{H}_{5}$ and $\mathrm{H}_{6}$ of $\beta$-CD were observed, suggesting that the A ring of entGCg was included in the $\beta$-CD cavity [25]. Upon the formation of the $1: 2$ inclusion complex of entGCg and $\beta-\mathrm{CD}$, all proton signals of entGCg were shifted upfield due to $\mathrm{C}-\mathrm{C}$ bond anisotropy by the two molecules of $\beta-\mathrm{CD}$. The proton signals of entGCg were broadened, except those for $\mathrm{H}_{6}$ and $\mathrm{H}_{2 ", 6 "}$ ( $\odot$ Fig. 15). A plausible explanation of the observed signal broadening may be due to the restricted motion of these protons by the two molecules of $\beta$-CD. Notably, the signal for the $\mathrm{H}_{2^{\prime}, 6^{\prime}}$ protons was markedly broadened, while that for the $\mathrm{H}_{2^{\prime \prime}, 6^{\prime \prime}}$ protons appeared sharp. These findings suggested that the $\mathrm{B}$ ring of entGCg was localized in the cavity of $\beta-\mathrm{CD}$, while the 3-O-gallate group ( $\mathrm{B}^{\prime}$ ring) was outside the cavity. Furthermore, the $\mathrm{H}_{8}$ signal almost disappeared on formation of the inclusion complex with $\beta-C D$, whereas the $\mathrm{H}_{6}$ signal was still sharp. The disappearance of the $\mathrm{H}_{8}$ signal may be explained by the close proximity with the hydrogens on the inner surface of $\beta$-CD. On the other hand, the motion of the $\mathrm{H}_{6}$ proton might not be restricted due to its position in the vicinity of the rim of the narrow primary hydroxyl group side of $\beta$-CD. It is therefore concluded that entGCg is enclosed in the two $\beta$-CD molecules in the manner illustrated in $\odot$ Fig. 15.

To confirm the structure of the $1: 2$ inclusion complex of entGCg and $\beta$-CD deduced from NMR experiments, the energies and structure of the $1: 1$ and $1: 2$ inclusion complexes were calculated using the PM5 MO method [31]. The 1:2 complex including the aromatic $A$ and $B$ rings of ent $\mathrm{GCg}$ is ca. $3 \mathrm{kcal} / \mathrm{mol}$ more stable than that including the $\mathrm{A}$ ring and 3-O-gallate group ( $\mathrm{B}^{\prime}$ ring) in the PM5 calculation ( $\odot$ Fig. 16).

EGCg and entGCg afforded no inclusion complex with $\alpha$-CD because the cavity of $\alpha-C D$ is not large enough to include these molecules. While EGCg yielded a 1:1 inclusion complex with $\beta$-CD, entGCg formed a $1: 2$ inclusion complex with $\beta$-CD, resulting from the different spacing between the $\mathrm{B}$ rings and the 3-O-gallate groups (B' rings) in aqueous solution. EGCg failed to form an inclusion complex with $\gamma$-CD, whereas entGCg did form a $1: 1$ inclusion complex with $\gamma$-CD due to the large cavity of $\gamma$-CD.

The difference in stereochemistry between EGCg and entGCg is only the configuration at the 2 position, but for the two mole- 


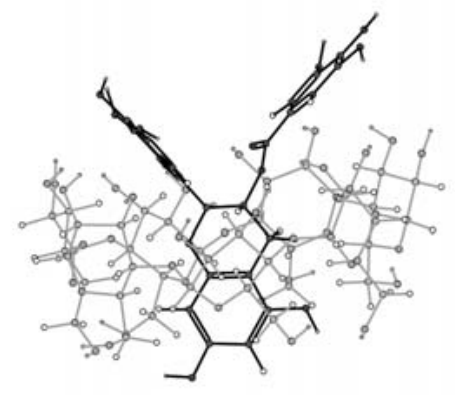

(1) 1:1 inclusion complex derived from ent $\mathrm{GCg}$ and $\beta-C D$ (A ring inclusion)

heat of formation $=-1993.90 \mathrm{kcal} / \mathrm{mol}$

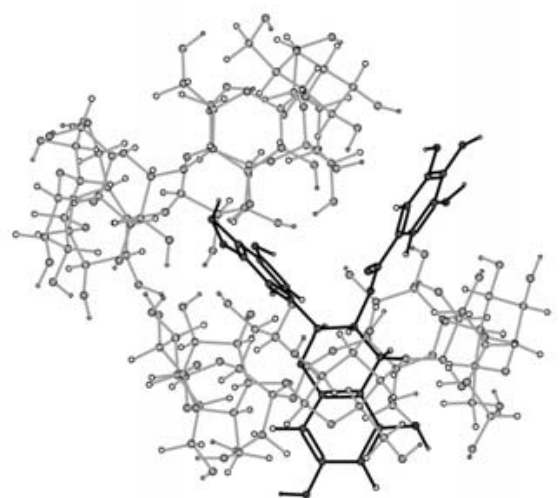

(2) 1:2 inclusion complex derived from ent $\mathrm{GCg}$ and $\beta-C D$ ( $A$ and $B$ ring inclusions)

heat of formation $=-3581.05 \mathrm{kcal} / \mathrm{mol}$

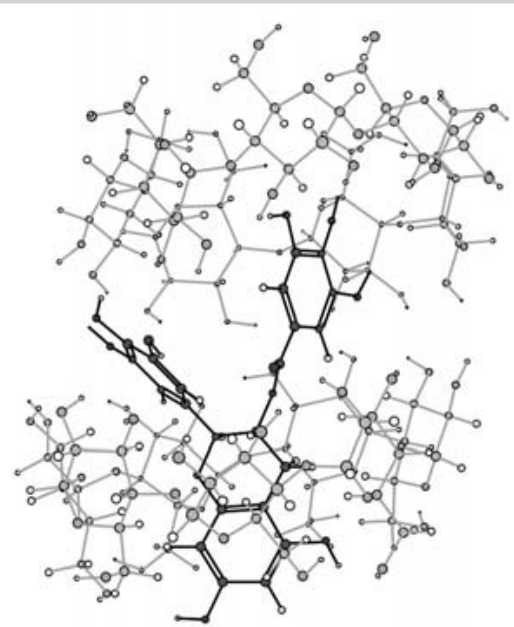

(3) 1:2 inclusion complex derived from ent $\mathrm{GCg}$ and $\beta-\mathrm{CD}$ ( $\mathrm{A}$ and $\mathrm{B}^{\prime}$ ring inclusions)

heat of formation $=-3578.45 \mathrm{kcal} / \mathrm{mol}$

Fig. 16 Structure of the $1: 1$ and $1: 2$ inclusion complexes of entGCg and $\beta$-CD by PM5 MO method.

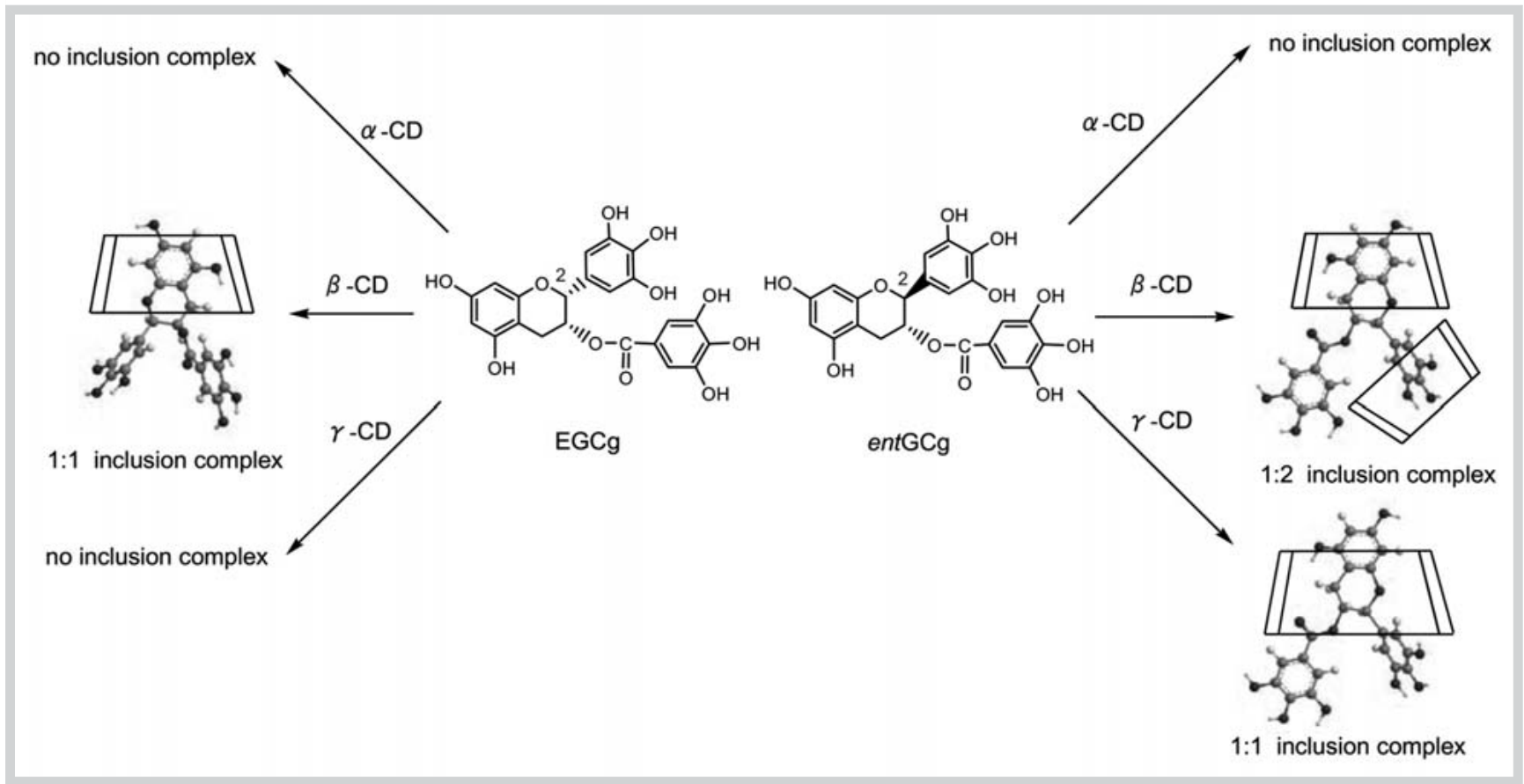

Fig. 17 Inclusion modes of EGCg and entGCg with $\alpha, \beta$, and $\gamma$-CDs.

cules the inclusion modes with various cyclodextrins vary considerably and are summarized in $\bullet$ Fig. 17.

\section{Supporting information}

X-ray data of the $1: 2$ and $2: 2$ complexes of entGCg and caffeine and entGCg alone, NMR experiments and calculation methods for the inclusion complexes of entGCg and $\beta$-CD are available as Supporting Information. 


\section{References}

1 Hemingway $R W$, Foo $L Y$, Porter $L J$. Linkage isomerism in trimeric and polymeric 2,3-cis procyanidins. J Chem Soc [Perkin I] 1982: 1209-1216

2 Porter LJ. Flavans and proanthocyanidins. In: Harborne JB, editor. The flavonoids: advances in research since 1980. London: Chapmann and Hall; 1988; 21-62

3 Kuroda Y, Hara Y. Health effects of tea and its catechins. New York, Boston, Dordrecht, London, Moscow: Kluwer Academic/Plenum Publishers; 2004: 11-60

4 Lambert JD, Yang CS. Cancer chemopreventive activity and bioavailability of tea and tea polyphenols. Mutat Res 2003; 523-524: 201-208

5 Ahmad N, Cheng P, Mukhtar H. Cell cycle dysregulation by green tea polyphenol epigallocatechin-3-gallate. Biochem Biophys Res Commun 2000; 275: 328-334

6 Maeda-Yamamoto M, Kawahara H, Tahara N, Tsuji K, Hara Y, Isemura M. Effects of tea polyphenols on the invasion and matrix metalloproteinases activities of human fibrosarcoma HT1080 cells. J Agric Food Chem 1999; 47: 2350-2354

7 Sazuka M, Imazawa H, Shoji Y, Mita T, Hara Y, Isemura M. Inhibition of collagenases from mouse lung carcinoma cells by green tea catechins and black tea theaflavins. Biosci Biotechnol Biochem 1997; 61: 15041506

8 Hashimoto F, Ono M, Masuoka C, Ito Y, Sakata Y, Shimizu K, Nonaka G, Nishioka I, Nohara T. Evaluation of the anti-oxidative effect (in vitro) of tea polyphenols. Biosci Biotechnol Biochem 2003; 67: 396-401

9 Kimura M, Umegaki K, Kasuya Y, Sugisawa A, Higuchi M. The relation between single/double or repeated tea catechin ingestions and plasma antioxidant activity in humans. Eur J Clin Nutr 2002; 56: 1186-1193

10 Hayashi $N$, Ujihara $T$. 'Biting effect' stabilizing gallate-type catechin/ quaternary ammonium ion complexes. Tetrahedron 2007; 63: $9802-$ 9809

11 Tezuka M, Suzuki H, Suzuki Y, Hara Y, Okada S. Inactivation effect of tea leaf catechins on human type-A influenza virus. Jpn J Toxicol Environ Health 1997; 43: 311-315

12 Okabe S, Suganuma M, Hayashi M, Sueoka E, Komori A, Fujiki H. Mechanisms of growth inhibition of human lung cancer cell line, PC-9, by tea polyphenols. Jpn J Cancer Res 1997; 88: 639-643

13 Miura S, Watanabe J, Tomita T, Sano M, Tomita I. The inhibitory effects of tea polyphenols (flavan-3-ol derivatives) on $\mathrm{Cu}^{2+}$ mediated oxidative modification of low density lipoprotein. Biol Pharm Bull 1994; 17: $1567-1572$

14 Hara Y, Watanabe M. Antibacterial activity of tea polyphenols against clostridium botulinum. Nippon Shokuhin Kogyo Gakkaishi 1989; 36: 951-955

15 Martin R, Lilley TH, Falshaw CP, Haslam E, Begley MJ, Magnolato D. The caffeine-potassium chlorogenate molecular complex. Phytochemistry 1986; 26: 273-279
16 Gaffney SH, Martin R, Lilley TH, Haslam E, Magnolato D. The association of polyphenols with caffeine and $\alpha$ - and $\beta$-cyclodextrin in aqueous media. J Chem Soc Chem Commun 1986; 2: 107-109

17 Horman I, Viani R. The nature and conformation of the caffeine-chlorogenate complex of coffee. J Food Sci 1972; 37: 925-927

18 Maruyama N, Suzuki Y, Sakata K, Yagi A, Ina K. NMR spectroscopic and computer graphics studies on the creaming down of tea. Proceedings of the International Symposium on Tea Science, Shizuoka-shi, Japan; 1991: 145-149

19 Cai Y, Gaffney SH, Lilley TH, Magnolato D, Martin R, Spencer CM, Haslam E. Polyphenol interactions. Part 4. Model studies with caffeine and cyclodextrins. J Chem Soc [Perkin II] 1990: 2197-2209

20 Hayashi N, Ujihara T, Kohata K. Binding energy of tea catechin/caffeine complexes in water evaluated by titration experiments with ${ }^{1} \mathrm{H}-\mathrm{NMR}$. Biosci Biotechnol Biochem 2004; 68: 2512-2518

21 Tsutsumi H, Sato T, Ishizu T. Offset $\pi-\pi$ interaction in crystal structure of (-)-gallocatechin-3-0-gallate. Chem Pharm Bull 2010; 58: 572-574

22 Ishizu T, Tsutsumi H, Sato T, Yamamoto H, Shiro M. Crystal structure of complex of gallocatechin gallate and caffeine. Chem Lett 2009; 38: 230-231

23 Ishizu T, Tsutsumi $\mathrm{H}$, Sato $\mathrm{T}$. Interaction between gallocatechin gallate and caffeine in crystal structure of $1: 2$ and 2:2 complexes. Tetrahedron Lett 2009; 50: 4121-4124

24 Wong JW, Yuen KH. Inclusion complexation of artemisinin with $\alpha-, \beta$ and $\gamma$-cyclodextrins. Drug Dev Indian Pharm 2003; 29: 1035-1044

25 Ishizu T, Kajitani S, Tsutsumi H, Yamamoto H, Harano K. Diastereomeric difference of inclusion modes between (-)-epicatechin gallate, (-)-epigallocatechin gallate and (+)-gallocatechin gallate, with $\beta$-cyclodextrin in aqueous solvent. Magn Reson Chem 2007; 46: 448-456

26 Ishizu T, Hirata C, Yamamoto H, Harano K. Structure and intramolecular flexibility of $\beta$-cyclodextrin complex with (-)-epigallocatechin gallate in aqueous solvent. Magn Reson Chem 2006; 44: 776-783

27 Ishizu T, Tsutsumi H, Yamamoto H, Harano K. NMR spectroscopic characterization of inclusion complexes comprising cyclodextrins and gallated catechins in aqueous solution: cavity size dependency. Magn Reson Chem 2008; 47: 283-287

28 Giacovazzo C. Fundamentals of crystallography, 2nd edition. IUCr texts on crystallography 7. Oxford: $\mathrm{IUCr} /$ Oxford University Press; 2002: 237-243

$29 \mathrm{Job} P$. Formation and stability of inorganic complexes in solution. Ann Chem 1928; 9: 113-203

30 Karplus $M$, Anderson DH. Valence-bond interpretation of electroncoupled nuclear spin interactions; application to methane. J Chem Phys 1959; 30: 6-10

31 WinMOPAC V3.9. Tokyo: Fujitsu Ltd; 2004 